\title{
Um campo para a criação: - desenvolvimento poético através do diário de pesquisa do pintor em formação
}

\author{
Poetics, creative processes and the \\ research journal of the painter in \\ training \\ Poética, procesos creativos y el \\ diario de investigación del pintor en \\ formación
}

\section{Martha Werneck ${ }^{1}$ \\ Lícius Bossolan²}

\footnotetext{
1 É Professora Adjunta do Curso de Graduação em Pintura da Escola de Belas Artes da UFRJ, Graduada em Pintura, com Mestrado e Doutorado em Artes Visuais, linha de pesquisa Imagem e Cultura. Site: www.anomia.art, E-mail: martha.werneck@gmail.com,

Currículo Lattes: http://lattes.cnpq.br/6702826238721394.

2 Nome artístico Lícius Bossolan, é Professor Assistente do Curso de Graduação em Pintura da Escola de Belas Artes da UFRJ, Graduado em Pintura e Mestre em Artes Visuais, linha de pesquisa Imagem e Cultura. Site: www.anomia.art, E-mail: liciusbossolan@gmail.com,

Currículo lattes: http://lattes.cnpq.br/3693755553577855
} 


\title{
Resumo
}

O artigo versa sobre o que tomamos por poética, tratando da importância do entendimento desse conceito para o ensino e metodologia aplicados em disciplinas práticas de ateliê, no Ciclo Básico do Curso de Graduação em Pintura da Escola de Belas Artes da Universidade Federal do Rio de Janeiro. O termo, que abarca tantas possíveis questões no universo das artes, é fundamental para aprofundar o trabalho de um estudante cuja formação é de um artista pesquisador em pintura. $\mathrm{O}$ artista é agente que pensa, propõe e transforma sua cultura e sociedade através de uma linguagem e justamente por isso é importante a consciência de seu campo poético, pois é ele que impulsiona a pesquisa, o ato criativo e a expressão. A poética que um estudante de pintura gesta e desenvolve funciona como principal catalisador de sua produção, norteando o processo criativo, a imaginação e a intuição. Além de tratar desse conceito, apresentaremos aqui a metodologia de ensino aplicada às turmas de segundo e terceiro períodos da graduação em Pintura. Esta propõe, através da elaboração de um corpo de imagens e de documentos de artista dos mais variados tipos, a organização do pensamento criativo em diários de pesquisa, também chamados sketchbooks. Esses suportes são como receptáculos que fomentam simultaneamente aprendizado, pesquisa e criação de estudantes iniciados nessa complexa, rica e ancestral linguagem: a pintura.

\section{Palavras-chave}

pintura; poética; processo criativo; metodologia; caderno de artista

\begin{abstract}
This article deals with what we consider to be poetics, clarifying the importance of understanding this concept in teaching and the methodology applied to practical studio subjects, in the Basic Cycle of UFRJ's - Federal University of Rio de Janeiro - Painting Course, School of Fine Arts. This designation, which covers so many possible concepts in the artistic field, is fundamental in deepening the work of an aspiring research artist in painting. The artist is a person who thinks, proposes and transforms his culture and society through a language. That is why it is important to be aware of your poetic field, as it is what drives research, creative act and expression. The poetics that a painting student creates and develops works as the main catalyst for his production, guiding the creative process, imagination and expression. In addition to addressing this concept, we will present here the teaching methodology applied to the classes of second and third periods of the Painting course. This proposes, through the elaboration of a cluster of images and artist documents of the most varied types, the organization of creative thinking in research journals, also called sketchbooks. These supports are like receptacles that simultaneously promote learning, research and creation of students initiated in this complex, rich and ancestral language: painting.
\end{abstract}

\section{Keywords}

painting; poetic; creative process; methodology; sketchbook

ISSN: 2447-1267 


\section{Resumen}

El texto trata de lo que consideramos como poética, abordando la importancia de comprender este concepto para la enseñanza y la metodología aplicada en las materias prácticas de estudio, en el Ciclo Básico del Curso de Graduación de Pintura en la Escuela de Bellas Artes de la Universidad Federal de Río de Janeiro. Esta palabra, que cubre tantos problemas posibles en el universo de las artes, es fundamental para profundizar el trabajo de un estudiante cuya formación es la de un artista investigador en pintura. El artista es un agente que piensa, propone y transforma su cultura y sociedad a través de un lenguaje y precisamente por eso es importante la conciencia de su campo poético, porque es él quien impulsa la investigación, el acto creativo y la expresión. La poética que un estudiante de pintura maneja y desarrolla actúa como el principal catalizador de su producción, guiando el proceso creativo, la imaginación y la intuición. Además de abordar este concepto, presentaremos aquí la metodología de enseñanza aplicada a las clases de segundo y tercer períodos del curso de pregrado en Pintura. Esto propone, a través de la elaboración de un cuerpo de imágenes y documentos del artista de los más variados tipos, la organización del pensamiento creativo en revistas de investigación, también llamados cuadernos de bocetos. Estos soportes son como receptáculos que simultáneamente promueven el aprendizaje, la investigación y la creación de estudiantes iniciados en este lenguaje complejo, rico y ancestral: la pintura.

\section{Palabras Clave}

pintura; poética; proceso creativo; metodología; cuaderno de bocetos 


\section{Imaginário e intuição: a poética como campo de investigações}

Lecionar disciplinas que tratam da criação artística e auxiliar o discente no desenvolvimento poético no campo da linguagem da pintura contemporânea significa estimulá-lo a desenvolver o seu trabalho como artista-pesquisador, enfoque central dos docentes do Curso de Pintura da Escola de Belas Artes da UFRJ.

Como docentes de disciplinas prático teóricas de ateliê no Ciclo Básico desse Curso, percebemos a importância da definição daquilo que compreendemos por poética e, da mesma forma, o avanço que o entendimento amplo desse conceito propicia ao ensino e ao melhor aproveitamento da metodologia que aplicamos. A formulação de propostas que possam fomentar o processo criativo de um estudante na prática da linguagem da pintura passa também pela experiência de ateliê de seus professores, artistas pesquisadores.

O conceito de poética, aprofundado por Paul Valéry na esteira de poetas como Baudelaire a Mallarmé, deriva de caracteres normativos e prescritivos da Poética Clássica, de Platão a Horácio que, somada à Poética Moderna traz à tona a necessidade de expressão da consciência crítica acerca do próprio processo artístico no sentido de analisar, teorizar, refletir, revelar e confessar os caminhos da criação. Um exemplo dessa atitude, mesmo que um pouco caricato, já que o autor chega a comparar-se a um matemático, é o texto de Allan Poe analisando a própria obra, O Corvo. Paul Valéry adota, acentua e aprofunda esse paradigma, denominando poética a simples noção do fazer. Em seus Cahiers, o caráter pessoal e autobiográfico é assumido, revelando prezar mais o fazer que seu próprio resultado ou produto. Para Valéry, o próprio poema é sua execução. "Porque é na execução das coisas que, para o poeta, o valor das coisas adquire legitimidade" (BRUTUS, p.134).

Ao pensar as questões relativas ao fazer artístico, Passeron define poiética como ciência e consciência das condutas criativas, como a construção de um pensamento que busca elucidar o fenômeno da criação, colocando a questão no campo da antropologia e chamando atenção para seus problemas epistemológicos. Afinal, como definir e analisar o processo de criação sendo o próprio criador? Nessa conduta o teórico reconhece subsistir certa obscuridade, parcial ou crepuscular, do artista em relação ao próprio trabalho. Logo, como ciência da observação, a poiética, que vem da palavra grega poïen, conduta, estará sempre, diríamos nós, à beira de um abismo de onde o artista mira a criação ao mesmo tempo em que a ela deseja se lançar.

No campo das artes visuais Sandra Rey aponta a relevante particularidade da pesquisa em poéticas visuais como diversa da pesquisa sobre arte como produto final. Essa modalidade na atividade acadêmica, presente no contexto universitário desde a década de 1980 quando instaurada na Universidade Paris I, se faz de forma concomitante à obra formulada. Para Rey, um projeto de pesquisa em artes visuais é tal qual um "(...) projétil, algo que é lançado com uma mira. Mas o caminho exato que irá percorrer nunca sabemos" (REY, p. 84). É justamente nessa particularidade, fugindo de uma estética que trata da metafísica da arte, que Pareyson pensa a análise da experiência estética do artista enquanto faz arte. Em Teoria da Formatividade 
ele propõe um conceito operativo que regule e oriente a experiência artística, entendendo que produção e invenção se fazem juntos, sendo a obra "lei e resultado de um processo de formação" (PAREYSON, p. 13). Esse processo, por seu dinamismo, está calcado na ação.

Enquanto docentes, nossas observações investigativas e toda a riqueza que atravessa a pesquisa por materiais, procedimentos e experimentações voltadas para as necessidades instrumentais e técnicas, além do amadurecimento de nossas próprias questões plásticas e semânticas, acabam impulsionando e motivando o ensino, possibilitando sempre uma reavaliação dos nossos métodos e de suas adequações. Ao realizarmos nossos trabalhos autorais somos motivados a produzir conhecimento, trazer à tona novas informações, descobertas particulares e metodologias de criação que são posteriormente aplicadas em ateliê coletivo, nossas salas de aula. Simultaneamente, levamos para nossos trabalhos as questões suscitadas por nossos estudantes, suas referências e achados, havendo aí uma constante e mútua retroalimentação. Tais experiências também nos fazem esbarrar, compreender e, até mesmo, relembrar dificuldades naturais que, por sua vez, são mais penosas para estudantes iniciantes, ainda desenvolvendo suas habilidades básicas.

Desse modo, atentos às propostas didáticas e à necessidade de aplicar um ensino individualizado da pintura, buscamos aperfeiçoar ao longo do tempo as metodologias para o desenvolvimento do trabalho criativo do pintor. Acreditamos que sua eficácia depende de uma elasticidade e relativa liberdade em relação às propostas apresentadas. Buscamos orientar os estudantes a pesquisarem o que apreciam no âmbito da pintura e, com isso, a formularem um ambiente de criação e imaginação para si. Somente desse modo eles poderão vislumbrar e desenvolver suas poéticas de forma mais consistente e consciente. É justamente sobre os percursos da criação, suas particularidades e a apreensão do universo criativo do pintor pesquisador contemporâneo que desejamos tratar neste artigo.

Para Gilbert Durand, o imaginário não pode ser encarado como uma disciplina individualizada e, portanto, desprovida de acesso "entre-saberes". Durand propõe considerar o imaginário dentro de uma interdisciplinaridade que, nessa concepção, se desdobra necessariamente em uma transdisciplinaridade.

O imaginário não é uma disciplina, (...). Radica no além, na realidade do modus imaginalis que, como outrora afirmei paradoxalmente a propósito do símbolo, é <<epifania de um mistério>>, faz ver o invisível através dos significantes, das parábolas, dos mitos dos poemas...(...). (DURAND, 1996, p. 243-244)

Da mesma forma que Durand define o imaginário como "um tecido conjuntivo $<<$ entre $>>$ as disciplinas, o reflexo - ou a $<<$ reflexão $>>$ ? - que acrescenta ao banal significante os significados, o apelo do sentido" (DURAND, 1996, p. 231), propomos a compreensão e o estudo da criação artística, assim como do desenvolvimento poético oriundo da pesquisa pictórica, como áreas do saber imersas em algo maior, algo para além de suas delimitações. 
Ainda precisamos salientar uma questão fundamental acerca da análise do próprio fazer, denominado por Jean Lancri claudicação ou posição mediana, assumida pelo agente criador. Atuando entre o sensível e o conceito, o artista pesquisador se articula entre prática, razão e sonho ${ }^{1}$. É na busca de conexões e de articulações entre esses campos envolvendo prática, questionamentos e problemas que o artista se coloca como se estivesse sempre alternando de posição, para analisar a si mesmo e retomar a prática artística.

Será necessário então estabelecermos um vocabulário que aprofunde os sentidos daquilo que queremos tratar.

O primeiro dos termos a tratar seria 'campo'. Dentro da criação artística costumamos empregar essa palavra para compreender o desenvolvimento do processo de criação e seu eixo condutor. Acreditamos que tal conceito auxilia na compreensão do que entendemos por poética, suas conexões, ramificações e desdobramentos.

Campo significa uma área, um espaço aberto que necessariamente não tem um limite definido. Suas margens podem ter contornos difusos, verdadeiras áreas cinzas que transitam entre diferentes valores tonais. Quando operamos o conceito de poética dentro desse entendimento queremos dizer que ela não é estática, rígida, mas sim fluida em suas conexões com aquilo que orbita ao seu redor. Essa transição imprecisa, apesar de termos um chão seguro e conhecido a princípio, confere à poética uma potencialidade para se expandir e desdobrar em novas investigações.

A essa altura o leitor deve ter reparado que conferimos à poética parâmetros espaciais, geográficos. Seu entendimento equivale a compreendê-la como constituída por uma área, uma superfície que tem centro conhecido, mas contornos e limites a serem explorados, mesmo que não sejam definidos ou exatamente conhecidos. De fato, é positivo que não o sejam, já que essa indefinição e fluidez nos fazem navegar, prosseguir com a pesquisa poética que pode, e deve, estar em construção constante.

Essa analogia converge para o conceito mais conhecido de campo de conhecimento, por onde transitamos e podemos tomar decisões, definindo em que direção seguir. Dessa forma, a poética pode ser tida como a área de conhecimento em que o artista opera conceitos e signos a partir de uma sequência de tomadas de decisão, objetivando um (in)determinado ${ }^{2}$ resultado para se expressar, comunicar e se conectar afetivamente com o que é criado. O que há de mais fantástico nisso tudoé podermos tatear por essa área sem sabermos ao certo para onde estamos indo. Assim descobrimos que esse plano, na verdade, é dado num espaço tridimensional, a ponto de abarcar questões diversas e amplas, que estejam acima ou abaixo dessa superfície. Um inconsciente aflora e estará sempre conectado à criação.

O processo de criação artística, portanto, opera entre campos que constituem a nossa psique e se inter-relacionam constantemente: o inconsciente, o consciente e a memória, essa constituída pela própria bagagem de experiência e conhecimento.

1 O leitor notará que mais adiante nos referiremos ao inconsciente do artista. O sonho, nesse caso, condiz com esse estádio do criador.

2 Observamos aqui a existência da dualidade determinado / indeterminado porque nunca sabemos ao certo o resultado de um trabalho de antemão, antes que seja considerado concluído pelo pintor. 
A consciência, por sua vez, cria questionamentos e atitudes que direcionam a investigação, mas sempre são balizados e equilibrados (ou sacudidos) pela intuição, poderoso guia que utiliza a ponte entre racionalidade e inconsciente. A intuição conduz, portanto, à inusitadas direções.

A artista e pesquisadora Fayga Ostrower aponta para a importância da procura por conhecimento ocorrer por meios racionais, mas sempre conectados à intuição, cujas raízes são inconscientes:

O impulso elementar e a força vital para criar provêm de áreas ocultas do ser. É possível que delas o indivíduo nunca se dê conta, permanecendo inconscientes, refratárias até a tentativas de se querer defini-las em termos de conteúdos psíquicos, nas motivações que levaram o indivíduo a agir. Além dos impulsos do inconsciente, entra nos processos criativos tudo o que o homem sabe, os conhecimentos, as conjecturas, as propostas, as dúvidas, tudo o que ele pensa e imagina. Utilizando o seu saber, o homem fica apto a examinar o trabalho e fazer novas opções. O consciente racional nunca se desliga das atividades criadoras; constitui um fator fundamental de elaboração. (OSTROWER, 2014, p. 55)

A constante parceria entre razão e intuição é a força motriz que nos alimenta e nos encoraja a ir em direção ao limite indefinido do campo poético, onde nos aprofundamos nas descobertas e desdobramentos dentro do sistema que operamos. A investigação consciente, equilibrada com a utilização da intuição, nebulosa, etérea, nos conduz ao amadurecimento poético e à sua constante reinvenção. Trata-se de pesquisa de imersão profunda, desenvolvida pelo imaginário de cada artista. Tal pesquisa é única e constitui uma verdadeira cartografia desenhada com terrenos de fronteiras líquidas, imprecisas.

Nesse sentido, Ostrower destaca que o papel da intuição é essencial e não deve ser descartado. Pelo contrário: é um modo de conhecimento que busca certa ordenação de significados. Torna-se, portanto, uma via fundamental de novas estruturações do artista e a ela deve ser dada importância e vazão:

A intuição vem a ser dos mais importantes modos cognitivos do homem. Ao contrário do instintivo, permite-lhe lidar com situações novas e inesperadas. Permite que, instantaneamente, visualize e internalize a ocorrência de fenômenos, julgue e compreenda algo a seu respeito. Permite-lhe agir espontaneamente. (OSTROWER, 2014, p. 56)

Ostrower conclui que a "intuição está na base dos processos de criação". Então, se a intuição possui papel de destaque nesse processo, parte da sua operacionalização é ter acesso constante ao inconsciente. Não podemos esquecer que atuamos no campo da visualidade e que a mente está constantemente criando imagens que influenciam e afloram do inconsciente.

Lancri, na mesma direção, evoca Merleau Ponty e Lévy Strauss para referir-se ao artista: entre o pensamento mágico e o conhecimento científico, o criador condensa na matéria o saber quando produz um objeto para o mundo. É nesse meio do caminho, 
entre o sonho e a razão, mencionados por Strauss em $\bigcirc$ pensamento selvagem, que o artista produz e se conecta ao imaginário e ao sonho.

Durand (2004), em seu ensaio sobre o imaginário, as ciências e filosofias da imagem, aborda os estudos de Sigmund Freud e aponta para sua descoberta fundamental sobre a existência e modos de como opera o inconsciente:

\begin{abstract}
A ideia e as experiências do "funcionamento concreto do pensamento" comprovaram que o psiquismo humano não funciona à luz da percepção imediata e de um encadeamento racional de idéias mas, também, na penumbra ou na noite de um inconsciente, revelando, aqui e ali, as imagens irracionais do sonho, da neurose ou da criação poética. (...) Os estudos clínicos de Freud e a repetição das experiências terapêuticas - o famoso "divã" comprovaram o papel decisivo das imagens como mensagens que afloram do fundo do inconsciente do psiquismo recalcado para o inconsciente. Qualquer manifestação da imagem representa uma espécie de intermediário entre um inconsciente não manifesto e uma tomada de consciência ativa. Daí ela possuir o status de um símbolo e constituir o modelo de um pensamento indireto no qual um significante ativo remete a um significado obscuro. (DURAND, 2004, p.35-36)
\end{abstract}

Pensar a poética, portanto, é estender o seu campo para áreas ainda ocultas, e percebê-las como tal é vital para o processo de criação. Nessa trajetória é importante estar atento a qualquer mecanismo de autocensura e, ao detectá-lo, saber lidar com ele. Sufocar a intuição, sem percebê-la, significa limitar a criação. Dessa forma, a intuição funciona como uma espécie de bússola-inconsciente que guia o artista nessas áreas sombrias; a razão, em contrapartida, reside na opção de prosseguir ou não naquela direção apontada e funciona como um outro instrumento guia, como um filtro, dessa vez consciente. Salles, através da crítica genética em arte, identifica que o artista vaga em uma direção, segue uma tendência. Assim, "o trabalho caminha para um maior discernimento daquilo que se quer elaborar. A tendência não apresenta já em si a solução concreta para um problema, mas indica o rumo." (SALLES, p.33).

Se compreendemos a pesquisa poética como proveniente do diálogo entre consciente, intuição, memória e inconsciente, desenvolver uma poética particular significa transitar em um mapa mental, de conceitos e visualidades em constante mutação, onde há a convergência e intercomunicação de duas áreas centrais para a construção da visualidade artística: a estética - aspecto formal, conectada à natureza da imagem - e o conteúdo semântico - que abrange o significado da imagem, seu simbolismo, tema etc.

A visualidade formativa da imagem (formas, cor, composição, relação altura/ largura da imagem, textura visual, a própria identificação da natureza da imagem, entre outros atributos) e o significado nela contidos são indissociáveis e materializam pouco a pouco a pesquisa poética. Para alimentar esse fluxo mental, o processo de criação pede para absorver imagens; olhar para outras imagens; saber ver imagens.

Dentro da metodologia que aplicamos em nossas próprias pesquisas pessoais em pintura, uma etapa fundamental e que observamos reincidir durante todo o 
desenvolvimento de nossos trabalhos autorais é a pesquisa de imagens referenciais. Consolidamos ao longo do processo de criação conjuntos de imagens que auxiliam na construção dos nossos campos poéticos.

A esse conjunto de imagens empregamos o conceito de 'corpo'; corpo de imagens. Com o agrupamento dessas imagens, reordenadas e constantemente observadas, traçamos interconexões, e assim vai se desenhando uma certa lógica nessas escolhas que apontam características sígnicas em comum. Tal conjunto de imagens cresce constantemente, como uma coleção compulsiva, agregando cada vez mais elementos que o fortalecem.

A importância de se criar um corpo de imagens referenciais é a de auxiliar a formar o olhar, potencializar um aprendizado que é natural do ser humano, tornandonos cada vez mais conscientes para potencializarmos nossas pesquisas poéticas.

A autora Fayga Ostrower explica esse fenômeno:

Desde cedo, organizam-se em nossa mente certas imagens. Essas imagens representam disposições em que, aparentemente de um modo natural, os fenômenos parecem correlacionar-se em nossa experiência. Dissemos "aparentemente natural" porque desde o início interligamos as disposições que se formam com atributos qualitativos que the são estendidos pelo contexto cultural. As disposições, imagens da percepção, compõem-se, a rigor, em grande parte de valores culturais. Constituem-se em ordenações "características" e passam a ser normativas, qualificando a maneira por que novas situações serão vivenciadas pelo indivíduo. Orientam o seu pensar e imaginar. Formam imagens referenciais que funcionam ao mesmo tempo como uma espécie de prisma para enfocar os fenômenos e como medida de avaliação. (OSTROWER, 2014, p. 58)

A partir do momento que, como pintores, buscamos e criamos nossos próprios corpos de imagens referenciais, vemos aflorar esse mecanismo cultural natural de aprendizado, o qual passa a balizar, segundo Ostrower, um novo "contexto de qualificações". Mais do que isso, cria-se um novo campo simbólico de atuação para a construção do imaginário e, consequentemente, da poética.

O agrupamento de inúmeras imagens parece trazer um campo semântico, ou campo simbólico como preferimos conceituar, e gera uma potencialidade de novos entendimentos, qualificações e ressignificações. Essa nuvem simbólica em suspensão, portanto com energia potencial pronta para entrar em movimento, pode ser traduzida pelo termo 'atmosfera' ou 'clima' da imagem, independente da natureza desta.

O pintor alemão Gerhard Richter adotou uma metodologia que evidencia a importância do corpo de imagens e da atmosfera gerada. Durante várias décadas, entre 1962 e $2013^{3}$, Richter reuniu e organizou centenas de fotos, recortes de jornais, tabelas de cor e sketchs, criando um grande arquivo de imagens que intitulou Atlas. Segundo Helmut Friedel (2007), Atlas apresenta várias séries de imagens que

3 O livro de Friedel indica 2006, mas como foi publicado em 2007, não traz a data atualizada que consta no site do artista. 
parecem perseguir uma narrativa em comum, circular, mas que podem ser lidas em várias direções.

Essa convergência "narrativa" apontada por Friedel, tão presente no corpo de imagens criadas ou selecionadas por Richter e que persistiu atravessando décadas, é o resultado de um eixo condutor único, mas em constante mutação, correspondente à presença da poética no processo de criação. A potencialidade de seus desdobramentos está presente na possibilidade de leituras em aberto e que se retroalimentam. Esse mecanismo somente se é possível com o corpo de imagens criado, com a atmosfera simbólica que transpira e se desdobra. A atmosfera é difusa, sem limites, mas é densa em sua manifestação simbólica. ${ }^{4}$

Ao analisar a psique humana, Carl Jung aborda o símbolo e analisa a sua forma operacional na mente. Jung não aborda o símbolo como pertencente ao entendimento semiótico de Charles Sanders Peirce (dentro das categorias sígnicas símbolo, ícone e índice), mas em um entendimento mais amplo e de limites indefinidos, podendo carregar um conteúdo que ele define como vago.

O que chamamos de símbolo é um termo, um nome ou mesmo uma imagem que nos pode ser familiar na vida cotidiana, embora possua conotações especiais além de seu significado evidente e convencional. Implica alguma coisa vaga, desconhecida ou oculta para nós. (JUNG, 2016. p.18). Assim, uma palavra ou uma imagem é simbólica quando implica alguma coisa além do seu significado manifesto e imediato. Esta palavra ou esta imagem tem um aspecto "inconsciente" mais amplo, que nunca é precisamente definido ou inteiramente explicado. E nem podemos ter esperanças de defini-lo ou explicá-lo. Quando a mente explora um símbolo, é conduzida a idéias que estão fora do alcance da nossa razão. (...) Por existirem inúmeras coisas fora do alcance da compreensão humana é que frequentemente utilizamos termos simbólicos como representação de conceitos que não podemos definir ou compreender integralmente. (JUNG, 2016. p.19)

Essas considerações de Jung sobre a natureza simbólica e a sua presença nos mecanismos do consciente e inconsciente, aliadas ao nosso entendimento de poética, nos auxiliam a compreender o potencial existente na criação do artista: ao operar dentro do seu campo poético e da atmosfera simbólica das imagens, o artista é capaz de acessar o campo oculto dos símbolos e trazer novas significações ao vago e desconhecido. Como agente criador, é capaz de intuir e concretizar novas possibilidades da manifestação simbólica da psique humana e realizar novas conexões entre elas.

4 Como exemplificação de alguns pintores e seus documentos de trabalho, citamos Daniel Senise com seus livros de anotações (SALLES, Cecília Almeida. Anotações de Daniel Senise: um canteiro de obras. ARS São Paulo, vol.1 n.2 São Paulo dez. 2003); Michaël Borremans, quando expõe o espaço do seu ateliê e seus documentos de trabalho no documentário A Knife in the Eye, de 2011 (disponível em https://www.youtube.com/ watch?v=dhhUmwmIMtc\&t=1939s, último acesso em 17 set. 2020); o texto do escritor e dramaturgo francês Jean Genet sobre Giacometti e seu espaço de criação (GENET, Jean. O ateliê de Giacometti. São Paulo: Cosac Naify, 2000); Lucian Freud, com o catálogo da exposição ocorrida no Centre Pompidou, mostrando o ateliê do artista e a relação de suas pinturas com seu ambiente de trabalho (The Studio, de DEBRAY, Cecile. Hirmer Verlag, 2010); materiais didáticos como fotografias autorais da casa e ateliê de Rembrandt, em Amsterdam, expondo alguns dos documentos de trabalho do pintor como objetos variados e coleções do artista. 
Assim, as imagens não se reduzem a uma síntese, não nos conduzem a um único significado, a algo que seja fixo. Elas exigem, como expõe Emmanuel Alloa (2015) ao se referir a Didi Huberman, um "um lapso de tempo e um lapso no tempo, um sobressalto, um pôr em movimento o olhar: uma sinestesia que precisa ser tomada ao pé da letra" (ALLOA, 2015, p.16). Eclode de cada imagem muito mais do que podemos apreender e organizar, pois pela imagem intuímos e somos tomados por sensações, direcionados em determinado sentido. Isso se dá porque uma imagem não se restringe a si mesma. Ela atua como mediadora de tempos, olhares e saberes, sendo impossível reduzi-la às questões técnicas e materiais. É a incerteza, a imprecisão de onde se localizam no âmbito do saber que dá a elas o poder de compor uma experiência em nosso imaginário. Uma imagem não tem início, meio e fim. Ela transcende os limites de suas bordas e se conecta a toda experiência que o observador possui. Aí ela se transforma e se expande.

Formar um corpo de imagens é um exercício que permite que as interconexões entre os componentes de um conjunto se façam de forma a transformar o olhar do artista pesquisador no sentido de evocar novos significados. $\bigcirc$ artista, cada vez que se volta a esse conjunto e passeia por cada uma dessas imagens, irá se deparar com uma atmosfera criada e encontrará novos sentidos e bifurcações, enriquecendo assim seu imaginário.

\section{Propostas e problemas}

Nas disciplinas que lecionamos, Criação Pictórica 2 e Pintura $1^{5}$, obrigatórias para os segundo e terceiro períodos, respectivamente, sempre estimulamos os estudantes a selecionarem referências, colhidas ao longo do período de acordo com uma proposta autoral. O objetivo é utilizar esses documentos de artista de acordo com exercícios específicos lançados em sala de aula, correspondentes às ementas ${ }^{6}$ das referidas disciplinas.

Nesse processo de busca o estudante é orientado a realizar um exercício de escrita, trabalhando a partir de palavras-chave que possam evocar sensações,

5 Essas disciplinas fazem parte do corpo central de disciplinas de ateliê do Curso de Graduação em Pintura da Escola de Belas Artes da UFRJ. A primeira é pré-requisito da segunda.

6 Ementa da disciplina Criação Pictórica 2: Compreensão e desenvolvimento da pintura como linguagem e como processo de pesquisa em constante amadurecimento poético, plástico e conceitual. Compreensão dos fundamentos básicos da pintura e do seu modus operandi como processo de construção e de criação de espaçoforma/cor. Aplicação de metodologia para a pesquisa prático-teórica, incluindo diário de pesquisa. Investigação da composição, dos elementos visuais e de suas relações com a poética. Aprofundamento do conceito da cor como fundamento regente da pintura - diferenciação da cor-luz da cor-pigmento, transparência/opacidade, cor quente/cor fria, saturação cromática, relações cromáticas. Ementa da disciplina Pintura 1: o uso dos materiais e do instrumental do pintor - dos suportes, dos pigmentos e de seus veículos. Lembramos que no Curso de Pintura há a disciplina Metodologia de pesquisa prático teórica em pintura, voltada para análise do processo de criação do artista. Nela são adotadas obras que trazem esse viés tais como: A criação plástica em questão, trazendo depoimentos de artistas brasileiros (AYALA, Walmir. A criação plástica em questão. Coleção Temas da Arte. Petrópolis: Vozes, 1970); Escritos de Artistas - Anos 60/70 (COTRIM, Cecilia; FERREIRA, Gloria. Escritos de Artistas - Anos 60/70. Rio de Janeiro: Zahar Editora, 2009), evidenciando a importância dos documentos de trabalho; textos como os escritos de Paul Gauguin, em Antes e Depois (GAUGUIN, Paul. Antes e Depois. Porto Alegre: L\&PM, 2011); Cartas a Theo, de Van Gogh (VAN GOGH, Vincent. Cartas a Theo. Porto Alegre: L\&PM, 2002.), entre outros. 
sentimentos, gostos e questões particulares a seu contexto, abarcando aquilo que gostaria de expressar. É através da palavra, da linguagem verbal já enraizada e familiar para um estudante de pintura, que o campo de representação se abre no âmbito daquilo que é visível e invisível, que está no âmbito da afetividade individual, configurando também um clima para o imaginário nascente. Como aponta Ostrower:

Assim como o próprio viver, o criar é um processo existencial. Não abrange apenas pensamentos nem apenas emoções. Nossa experiência e nossa capacidade de configurar formas e de discernir símbolos e significados se originam nas regiões mais fundas de nosso mundo interior, do sensório e da afetividade, onde emoção permeia os pensamentos ao mesmo tempo que o intelecto estrutura as emoções. São níveis contínuos e integrantes em que fluem as divisas entre consciente e inconsciente e onde desde cedo em nossa vida se formulam os modos da própria percepção. São os níveis intuitivos do nosso ser. (OSTROWER, 2014, p. 56)

A partir da análise dessas palavras e de seus sentidos são formados conjuntos semânticos que, por sua vez, guiam buscas por imagens que remetem a essas ideias, formando um corpo de imagens que passam a funcionar como referências primordiais. Essas buscas podem ser de qualquer natureza. Alguns estudantes fazem ensaios fotográficos, outros trabalham com objetos utilizados para exercícios de observação, mas a expressiva maioria trabalha a partir dos motores de busca virtual do Google e de plataformas de imagens como o Pinterest e Instagram. ${ }^{7}$ Também como referências podem ser tomadas imagens do universo da propaganda, da estamparia, fotogramas fílmicos, embalagens de produtos entre outros.

Através desse exercício que envolve delimitações, escolhas e buscas, a intuição e a racionalidade entram em consonância para que se apresentem caminhos do campo criativo, definindo de forma rasa, ainda neófita, apontamentos para a poética do artista que se aprofundam, à medida que o trabalho autoral é desenvolvido. A partir desses documentos o estudante desenvolverá obrigatoriamente estudos autorais de composição lineares e tonais, feitos a lápis e carvão respectivamente, além dos estudos rápidos em tinta a óleo sobre papel kraft.

Nessas disciplinas os estudantes também são estimulados a estudarem composições, fatura da pincelada e as relações cromáticas de um pintor com quem se identifiquem através da estética, não necessariamente pelo tema ${ }^{8}$ abordado. Convencionamos chamar esse ponto de referência, na pesquisa de cada estudante, de 'pintor âncora', pois suas pinturas serão base para estudos de processo e cromatismo nos trabalhos autorais desenvolvidos durante o semestre. Há também, em nossa proposta, a escolha dos 'artistas suporte', que deverão ter algo em comum com o tema

7 Observamos, é importante frisar, que imagens impressas, mesmo em impressoras caseiras de qualidade mediana, trazem melhores resultados como referências do que as imagens em suporte eletrônico, como telas de celulares e tablets. Isso ocorre porque a luminosidade dos aparelhos e sua reduzida tela com possibilidade de ampliação acabam atrapalhando o estudante iniciante na visualização e relativização de cores e proporções.

8 Explicamos ao estudante que 'tema' não é equivalente à 'poética', sendo essa mais ampla, complexa e que leva em consideração a estética e visualidade da imagem, conforme explicamos anteriormente. 
escolhido a ser desenvolvido pelo estudante. Esses últimos não são necessariamente pintores. Sugerimos que o pintor âncora seja um artista já reconhecido na História da Arte tradicional ou contemporânea, tendo sido o seu trabalho fartamente documentado, facilitando o acesso do discente à sua obra. Também incentivamos que o estudante adquira um pequeno livro desse artista para com ele seguir durante os semestres. No entanto, cabe ressaltar que é plenamente possível uma mudança e redirecionamento, caso caiba na proposta do discente. Temos que ter em mente que a pesquisa poética é mutável, podendo absorver novas direções.

Apesar de nossos esforços para transmitir essa metodologia, vínhamos observando problemas frequentes relacionados à organização dos documentos de trabalho, algo que impactava fortemente nossas análises. A ausência de um sistema mais claro para a disposição e visualização do material e dos estudos de pintura tornavam difíceis as avaliações, prejudicando também a didática.

Notamos que a falta de cuidado e de apuro para com o material gerado durante os exercícios, realizados em ateliê coletivo, e a ausência de sequencialidade cronológica em sua organização, levava à insuficiência de anotações, apontamentos, datas e entendimento desses estudos rápidos. Eles não eram tomados como projetos, como treinamento do olhar e materialização da reflexão poética. Também não tinham espaço pleno para o desenvolvimento dos estudos de paleta, de harmonia cromática, de apontamentos que tratam de escolhas compositivas.

Frequentemente os estudantes não carregavam consigo os exercícios desenvolvidos em óleo sobre papel kraft, que costumamos usar por sua durabilidade, resistência e tonalidade. Ao longo do semestre tratavam com indulgência as imagens de referência para suas pinturas, assim como os estudos feitos em papéis avulsos do tipo Canson A4 voltados para as estruturas linear e tonal de suas composições, tratando-os como se fossem pouco importantes.

Ao fim do semestre, os menos caprichosos entregavam uma pasta cheia de trabalhos desordenados que deveriam ser decifrados pelo professor. Tais trabalhos, ao longo do período, estiveram ausentes do processo de aprendizagem por esquecimento ou falta de entendimento mais profundo da formação poética. Além disso, como é natural para quem está aprendendo e se familiarizando com a linguagem pictórica, muitos desses estudos possuem problemas de construção, de composição, de cor e, infelizmente, alguns estudantes os omitiam na entrega do conjunto final, ou os descartavam, como se não fossem parte do processo. Deixávamos então de observar questões essenciais que ajudariam no desenvolvimento do olhar.

Costumamos dizer que, na pintura, um trabalho se prolonga no seguinte; é um processo contínuo. A sequência de estudos e de propostas geralmente retém a chave de muitos processos de criação e expõem saltos no entendimento acerca da linguagem e de seus elementos mais sutis. A solução que aparece em um exercício anterior, pode apontar para um melhor resultado em outra pintura, a ser realizada alguns dias depois. Sem esse material em mãos, organizado de forma sequencial, perdíamos o processo criativo em desenvolvimento, o fio do raciocínio e os possíveis apontamentos que poderiam ser feitos, caso o estudante estivesse sempre acompanhado por seu material. 
$\mathrm{Na}$ ausência de uma metodologia mais cuidadosa, parte importante do processo de criação acabava se perdendo, em especial a elaboração e organização dos documentos do artista, a que chamamos frequentemente de referências, e a análise mais detida dos trabalhos do pintor âncora. Assim, o registro incompleto do processo poético e o arquivamento inadequado do seu desenvolvimento prejudicavam muito o estudante em relação ao seu posicionamento crítico e mais consciente sobre seu próprio trabalho.

\section{O diário de pesquisa como ponto de convergência:}

Ao detectarmos essas questões sempre recorrentes, decidimos abrir espaço para experimentações que, impulsionadas por nossa pesquisa poética e trabalhos autorais, viriam a apontar soluções para condensar o pensamento plástico do estudante, seu desenvolvimento de ideias e projetos, seus interesses e suas propostas. Assim, concluímos que o melhor método seria utilizar como ferramenta da memória o sketchbook ou diário de pesquisa, assim por nós denominado por conter em si uma sequencialidade temporal da criação.

Com o objetivo de tornar esse processo claro, nos propusemos a trabalhar em nossos próprios diários, adotando essa direção. Assim, além de continuarmos a produção em nossos antigos cadernos, passamos a pesquisar e a adquirir diferentes tipos e marcas de fabricantes dos chamados sketchbooks: dos mais em conta para essa finalidade, como os da marca Canson, com papel de gramatura baixa, aos Moleskines importados, com capa de couro e papel mais encorpado, mas liso.

Ao longo de alguns meses, dedicamos parte do tempo de pintura em ateliê realizando estudos variados nesses cadernos. Experimentamos a tinta a óleo sobre papel do próprio caderno, além de procedimentos como o isolamento do papel do caderno com tinta acrílica em spray, visando dar à superfície proteção ${ }^{9}$ e imprimação colorida. Também realizamos inúmeros desenhos, anotações, estudos de paleta e colagens que nos levaram à solução mais adequada para os estudos a óleo direcionados aos iniciantes: o papel kraft 180gr. Esse suporte já tinha sido testado anteriormente por nós com sucesso e identificado como adequado por justamente nos propiciar a trabalhar imprimações de diversas cores, assim como, de forma crua, a fornecer cor de fundo neutro, tão útil para o aprendizado das opacidades na pintura. Após secos, esses estudos, feitos em formatos menores que o A4, passaram a ser incorporados ao caderno como colagens.

Observamos também que o uso de papel vegetal, posicionado entre as pinturas ainda levemente úmidas e as folhas do caderno, ajudam a preservar o material, sem danos à pintura fresca. Também observamos custo-benefício de cadernos feitos artesanalmente e dos fabricados pela Canson formato A4. Esses últimos, com papel

9 A tinta a óleo é material com pH ácido que degrada a celulose ao longo do tempo. Adicionar uma camada adicional de tinta acrílica auxilia a proteger e impermeabilizar a superfície do papel. 
$100 \mathrm{~g} / \mathrm{m}^{2}$, são ótimos para estudos em lápis e carvão e suportam a tinta a óleo se usada com cuidado, sem muito molho ${ }^{10}$. Também são úteis para as anotações diversas, tão importantes para os estudantes em formação nesses períodos básicos.

Após essa pesquisa de material aplicada às nossas práticas, os cadernos foram levados à sala de aula como ideias de desenvolvimento para os estudantes. Como material didático dessa metodologia, acrescentamos a apresentação de imagens de cadernos de outros artistas. Com essas exemplificações, imersos em uma pesquisa poética própria, cada estudante começa a vislumbrar como pode desenvolver seu diário de pesquisa, de forma a produzir um ambiente particular de criação.

Com a obrigatoriedade da adoção dessa ferramenta, acabamos conduzindo a produção discente à organização dos documentos, estudos e, sobretudo, pensamento do artista em formação. A partir desse aprendizado inicial, cada um cria seus próprios métodos, individualizando sua forma de organização e construindo conjuntos de imagens impressas, eventuais desenhos de observação, rápidos esboços, anotações sobre o processo de trabalho, registros de paleta, apontamentos acerca do seu tema, pensamentos acerca da elaboração da poética, estudos de composições autorais lineares e tonais (abordando o claro escuro) com diversas variações, pequenos e rápidos estudos dos trabalhos do pintor âncora, notas acerca das relações cromáticas que está utilizando, entre outros. O diário de pesquisa funciona como laboratório e registro de experiências criativas, condensa a atmosférica simbólica pesquisada.

Além de materializar a pesquisa e as investigações de cada estudante dentro de um campo poético, o diário de pesquisa muitas vezes torna-se instrumento para além das disciplinas em que é requerido, pois o estudante é orientado a tratar esse material da forma que considere mais adequada. Isso inclui, muitas vezes, outros usos igualmente interessantes e singulares que marcam o tempo e a formação do seu olhar investigativo e criador.

Assim, concluímos que cabe no ensino estruturado da linguagem da pintura uma metodologia que permita um panorama daquilo que o estudante produz, que fomente sua pesquisa autoral. $\bigcirc$ atendimento individualizado só se realiza factualmente através do conjunto de trabalhos que vão respondendo às propostas didáticas mais ou menos abertas (limitadas de acordo com as ementas das disciplinas), propiciando a apreciação da temporalidade da produção pelo docente e pelo discente. A operação do acaso, os bons resultados e dificuldades podem ser assim visualizados, compreendidos num conjunto mais amplo se relativamente bem organizado. A intuição manifestada, que move o artista em formação, pode então ser reveladora e apresentar um gancho para apontamentos, desdobramentos e aprofundamento de compreensões das mais diversificadas naturezas: das questões semânticas às questões plásticas mais elementares e estruturantes.

Observar o corpo do processo criativo de forma clara permite, sobretudo, o apuro do olhar, a análise do próprio trabalho e, por fim, uma autocrítica positiva e 
otimista por parte do estudante, algo que notamos muito valioso dado que a pintura é uma linguagem complexa, que precisa de prática extensa para amadurecer e apresentar melhores resultados. É visível, através dessa metodologia, o avanço e o amadurecimento do olhar do estudante ao longo dos períodos, algo que os estimula a seguir em frente. Ela propicia, portanto, uma ferramenta que potencializa a possibilidade de estabelecer distanciamento, de fazer o que Lancri chamaria de "desvio pelo outro" (LANCRI, p.20), a partir do momento em que os diários de pesquisa transitam entre os estudantes, evidenciando procedimentos e pesquisas de outros artistas pesquisados e dos próprios colegas.

Nosso intuito, com isso, é ensinar o discente a observar como o desenvolvimento metodológico é fundamental para a elaboração do seu trabalho de forma consistente. Para além da transmissão de conceitos com os quais o estudante pode operar, como a própria poética e seus desdobramentos, focamos na importância do entendimento desses mecanismos como pontos de partida que evitam apagões criativos ou a tal e mítica 'ausência de inspiração'. Assim, essa primeira experiência mais direcionada funciona como um catalisador para o desenvolvimento de outras metodologias individualizadas, criadas pelo próprio artista, visando atender suas necessidades de pesquisa, sempre o mantendo em movimento criativo.

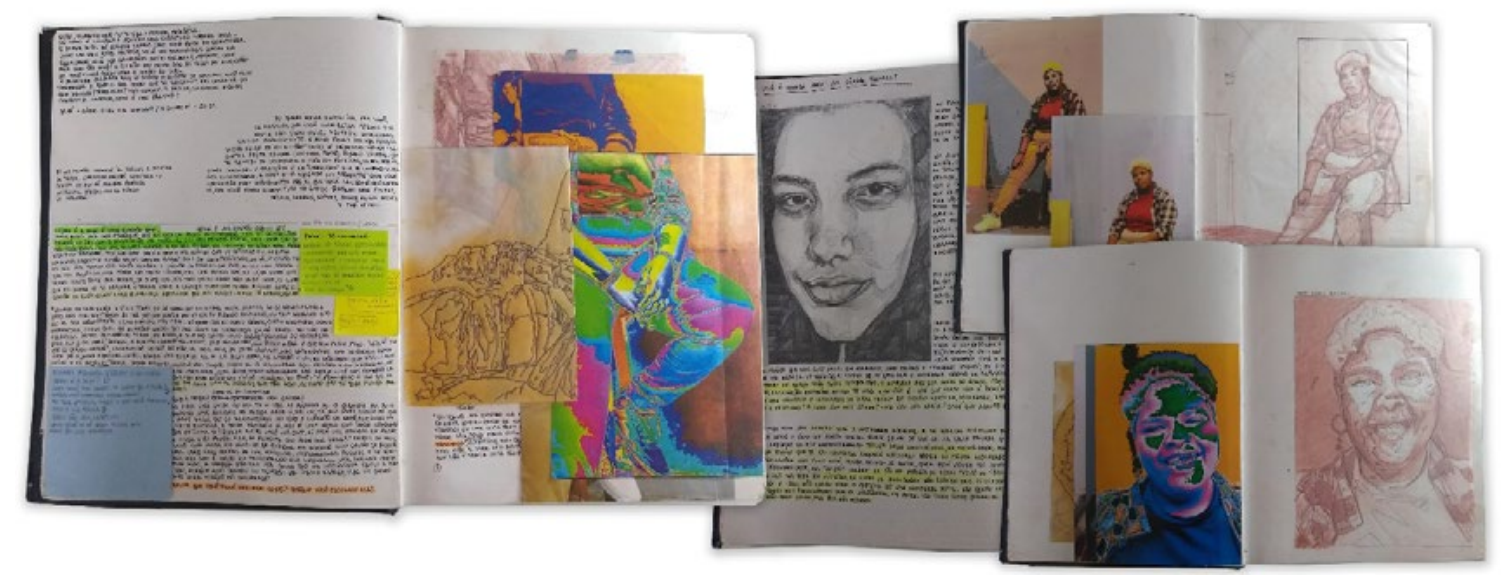

Fig. 1, páginas do diário de pesquisa A4 de Revelyn Veloso, estudante do sexto período do Curso de Pintura / EBA - UFRJ. Fotos: Revelyn Veloso.

O diário de pesquisa veio, desse modo, a condensar etapas importantes do processo criativo do discente e a conduzir suas investigações durante alguns períodos letivos na universidade ${ }^{11}$. Embora alguns artistas em formação abandonem esse material como ferramenta ao longo da graduação, muitos passam a considerá-lo parte fundamental de suas criações.

Com esse método o artista constrói para si um campo imaginário e de pesquisa, rememora seus percalços e acertos, suas descobertas e observa o crescimento do conhecimento visual, prático e teórico. Fica ali o registro da atmosfera poética sempre em formação e, impulsionado pela busca constante, prossegue por fronteiras indefinidas, se redirecionando constantemente. Produz, assim, um saber em 
movimento, reflexivo sobre o próprio trabalho e interessado por manter a pesquisa viva, como parte imprescindível do fazer artístico.

\section{Referências}

ALLOA, Emmanuel (org.). Pensar a Imagem. Belo Horizonte: Autêntica Editora, 2015.

BRUTUS, Abel. Paul Valéry - Estudos filosóficos, Tese (Doutorado), Departamento de Filosofia, Faculdade de Filosofia, Letras e Ciências Humanas, Universidade de São Paulo, São Paulo, 2008.

DURAND, Gilbert. O Imaginário: ensaio acerca das ciências e da filosofia da imagem. Rio de Janeiro: DIFEL, 2004.

DURAND, Gilbert. Campos do Imaginário. Coleção Teoria das Artes e Literatura. Lisboa: Ellug, 1996.

FRIEDEL, Helmut. Gerhard Richter: Atlas. New York: D.A.P./Distributed Art Publishers, 2007. JUNG,Carl G. (et.al). O Homem e seus símbolos. Rio de Janeiro: Harper Collins Brasil, 2016. LANCRI, Jean. "Colóquio sobre a metodologia da pesquisa em artes plásticas na universidade". In: BRITES; TESSLER (org.). O meio como ponto zero. Coleção Visualidade 4. Porto Alegre, Ed. Universidade/UFRGS, 2002.

OSTROWER, Fayga. Criatividade e Processos de Criação. Petrópolis: Vozes, 2014.

PAREYSON, L. Estética, teoria da formatividade. Petrópolis: Vozes, 1991.

PASSERON, René. A poiética em questão. In: Porto Arte. Porto Alegre, v. 13, n. 21, p.09-15. 2004.

POE, Edgar Allan. Poemas e Ensaios. São Paulo: Globo, 1999.

REY, Sandra. "Da prática à teoria: três instâncias metodológicas sobre a pesquisa em poéticas visuais". In: Porto Arte. Porto Alegre, v. 7, n. 13, p.81-95. nov.1996.

SALLES, Cecília Almeida. Gesto inacabado: processo de criação artística. São Paulo: FAPESP: Annablume, 2004.

Recebido em 01 de agosto de 2020.

Aprovado em 17 de agosto de 2020. 